\section{Training phoneme blending skills in children with Down syndrome}

\title{
Kelly Burgoyne
}

University College London, UK

\section{Fiona Duff and Maggie Snowling}

University of Oxford, UK

\section{Sue Buckley}

Down Syndrome Education International, Kirkby Lonsdale, Cumbria, UK

\section{Charles Hulme}

University College London, UK

\begin{abstract}
This article reports the evaluation of a 6-week programme of teaching designed to support the development of phoneme blending skills in children with Down syndrome (DS). Teaching assistants (TAs) were trained to deliver the intervention to individual children in daily $10-15$-minute sessions, within a broader context of reading and language instruction. Ten children with Down syndrome (aged 6 years II months to 10 years 6 months) took part in the study; assessments of reading and phonological skills were completed at baseline, after an 8-week control period, and after 6-weeks of intervention. Children made significantly greater gains in phoneme blending skills and single word reading during the intervention period than in the control period. Thus, children with Down syndrome can make gains in blending skills, which may generalize to wider literacy skills, following targeted training over relatively short periods.
\end{abstract}

\section{Keywords}

Blending, Down syndrome, intervention, phonological awareness, reading

\section{Introduction}

Many children with Down syndrome (DS) can learn to read, although there is wide variability in attainment levels (Hulme et al., 2012; Kay-Raining Bird and Chapman, 2011; Laws and Gunn, 2002).

Corresponding author:

Kelly Burgoyne, University College London, Division of Psychology and Language Sciences, Chandler House (Rm G05), 2 Wakefield Street, London WCIN IPF, UK.

Email: k.burgoyne@ucl.ac.uk 
For this group, whole-word reading skills are typically better than are skills in decoding as assessed by measures of non-word reading. These difficulties in developing decoding skills appear related to impairments in phonological awareness (Kay-Raining Bird et al., 2000; Lemons and Fuchs, 2010a, 2010b; Roch and Jarrold, 2008). Such difficulties may be interpreted as reflecting a difficulty with phonological reading strategies in contrast to relatively strong visual or whole-word reading skills.

The skills and strategies that children have available to them to support reading are clearly affected by reading instruction. Historically, when teaching children with DS to read, instruction has tended to favour whole-word teaching methods building on visual learning strengths (Fidler et al., 2005). Whole-word teaching can effectively increase the number of words children recognize; however, it does not equip children with strategies to enable them to work out how to read new and unfamiliar words for themselves. Potentially, this tendency towards whole-word approaches to reading instruction contributes to the pattern of strengths and weaknesses observed in the reading skills of children with DS (Kay-Raining Bird et al., 2000; Lemons and Fuchs, 2010a).

Two foundational skills that are important for reading development are letter-sound knowledge and phoneme awareness (Muter et al., 2004). These skills can be applied when children encounter new words in print: by sounding out the letters and blending those sounds together children can read new unfamiliar words. This constitutes a phonic approach to reading. Skills in phoneme blending (an aspect of phoneme awareness) are therefore of particular importance for learning to read. There is good evidence to support the benefits of systematic phonics instruction (including training in phoneme awareness) for improving reading (NRP, 2000; Torgerson et al., 2006), such that phonics instruction (within a language-rich curriculum) is strongly recommended as the primary approach to reading in the UK (Rose, 2006).

Recent research suggests that phonological awareness and phonics-based reading instruction can also be effective for many children with DS (e.g. Baylis and Snowling, 2012; Cologon et al., 2011; Goetz et al., 2008; Lemons and Fuchs, 2010a; van Bysterveldt et al., 2006). In the largest evaluation of reading and language intervention for children with DS to date (Burgoyne et al., 2012a), children made significantly greater gains in single word reading following 20 weeks of comprehensive phonics-based reading instruction combined with targeted language work, in comparison to typical classroom literacy instruction. Nonetheless, phonological skills and decoding remained challenging for many of these children: no significant gains were made in non-word reading or spelling, and slower growth was reported on measures of phoneme blending and letter-sound knowledge after the initial phase of intervention.

The teaching programme evaluated by Burgoyne et al. (2012a) was delivered by trained teaching assistants (TAs) who selected specific teaching targets and activities based on individual children's needs and abilities. These could include work at the syllable and rime levels as well as phoneme level activities, and activities targeting alliteration and matching skills, as well as blending and segmenting. Thus, the actual content of teaching was variable and some children may have received little direct work on phoneme blending skills even though these are particularly important for decoding. Evidence of difficulties with phoneme level skills in children with DS has been reported elsewhere (e.g. Kay-Raining Bird et al., 2000). Taken together this suggests that a teaching programme which specifically targets these skills may be beneficial for children with DS.

In the current study, a teaching programme to support the development of phoneme blending skills in children with DS was devised and evaluated. As teaching assistants report that they find the teaching of phonics difficult (Burgoyne et al., 2012b; Carroll et al., 2011), we developed a scripted programme that specifically targeted phoneme blending and was considered easy to implement. The specific research questions were:

- Can a targeted teaching programme improve the phoneme blending skills of children with DS?

- Does the programme lead to gains in reading and spelling? 
- Do educators working with children with DS feel the programme is easy to implement, effective and worthwhile?

\section{Method}

Trained TAs delivered a 6-week intervention to support phoneme blending skills to individual children in daily $10-15$ minute sessions in school. A case series research design was used whereby each child acted as their own control. Ethical approval was granted by the Research Ethics committee, Department of Psychology, University of York; informed parental consent was obtained for all children.

\section{Participants}

Ten children ( 8 boys) with DS were recruited from a cohort of 57 children who had previously participated in a larger study of reading and language intervention (Burgoyne et al., 2012a). Recruitment was based on the following criteria:

- TAs working with the children expressed interest in taking part and reading continued to be a target for instruction in school.

- At the latest assessment (January 2011) children correctly identified a minimum of 15 lettersounds, and attained word reading/phoneme blending scores that were below ceiling; and

- Children had good attendance (minimum of 50\% attendance rate) during the reading and language intervention.

Descriptive statistics on key reading and language measures at time 1 (t1; July 2011) are displayed in Table 1. The children were aged between 6 years 11 months and 10 years 6 months (mean age 8 years 4 months) at t1. All attended mainstream primary school with support from a TA and had previously received reading and language intervention as part of the larger study for either 40 $(n=4)$ or 20 weeks $(n=6)$.

\section{Intervention programme}

The teaching programme (30 sessions) was designed to be delivered in daily $10-15$-minute sessions with individual children. The content followed a clear, structured progression based on the sequence of phonemes outlined in Letters and sounds (DfES, 2007). Each teaching session followed a prescribed format of six activities introducing $2-3$ new letter-sounds every second day. Content increased in difficulty with vowel digraphs introduced in week 4 and consonant clusters in week 5. The activities involved the blending of 2- and 3-phoneme words in order to minimize cognitive load; TAs were provided with a list of 4-phoneme target words that could be used to increase the difficulty level if they felt this was appropriate. An overview of the programme structure and sequence is provided in Appendix 1.

Six teaching activities, based on similar tasks used in previous research (e.g. Cologon et al., 2011; Lemons and Fuchs, 2010a) were followed each day in a regular sequence (see Table 2 and example of scripted teaching session in Appendix 2). The language used by teaching assistants was kept consistent across activities to support the transfer of skills. Blending of individual phonemes/letter-sounds was practised both aurally (providing practise in listening to sounds) and with letters (to make the connection with reading explicit). Pictures were used to support some of the activities to reduce cognitive load, link the words to oral language and enable a non-verbal response; blending activities without 
Table I. Descriptive statistics for key reading and language measures at $\mathrm{tl}$ (July 20II).

\begin{tabular}{lccl}
\hline Test (maximum score) & Mean & Range & Mean age equivalent \\
\hline Letter-sound knowledge (32) & $24.80(4.13)$ & $18-31$ & $5 ; 2$ \\
Word reading (79) & $14.00(9.01)$ & $1-35$ & - \\
Phoneme blending with pictures $(10)^{*}$ & $7.70(1.83)$ & $5-10$ & - \\
Expressive vocabulary $(170)$ & $48.90(14.11)$ & $32-74$ & $4 ; 8$ \\
Receptive vocabulary $(170)$ & $52.80(9.31)$ & $44-72$ & $4 ; 7$ \\
\hline
\end{tabular}

Note. *Where chance performance is 3.33 .

Table 2. Teaching activities.

I Visual blending with pictures

2 Visual blending

3 Oral blending with pictures

$4 \quad$ Oral blending

$5 \quad$ Non-word reading

6 Sentence reading
Teaching assistants (TAs) placed individual letters in front of children to spell out a word; the child produced the sound for each letter then blended the sounds to make the word. The child selected which one of three pictures matched the word.

TAs placed individual letters in front of the child to spell out a word; the child produced the sound for each individual letter then blended the sounds together and said the word.

TAs sounded out a word; the child blended the sounds together to make the word and pointed to one of three pictures which matched the word.

TAs sounded out a word; the child blended the sounds together and said the word.

The child was shown a picture of a cartoon monster under which was a non-word. The child was asked to sound out and blend the sounds together to read the monster's name.

The child was shown a sentence which contained a decodable word which was marked out with sound buttons placed under each phoneme. The child was asked to read the sentence and to sound out/ blend the decodable word, then to read the whole sentence again.

picture support were also included to reflect real reading experiences. Non-word reading activities provided further practise in sounding out/blending letters. Lastly, a sentence reading activity was used to highlight the link between sounding out/blending and reading in context. There was scope within the programme to adjust the difficulty level of the teaching activities depending on the child's ability: for example, by reducing the number of word targets within each activity; increasing/decreasing the level of TA support; or reading only the decodable word versus the whole sentence in the final activity.

TAs were provided with all resources and materials to deliver the teaching. The design of the intervention and training took advantage of a number of strategies that increase fidelity to intervention (Kaderavek and Justice, 2010):

- The intervention was scripted and followed a standard format with clear teaching targets for each activity (for example, see Appendix 2).

- TAs were provided with a teaching manual and training (delivered via a DVD), which included a demonstration of each of the teaching activities.

- TAs were observed in weeks 2-3 of intervention for ongoing support/follow-up training. 
Fidelity to intervention was evaluated during observations by rating TAs on 10 items measuring effectiveness of delivery and adherence to the programme using a scale of 1 (excellent) to 3 (poor); the average TA rating was 1.31 .

All children completed all teaching sessions (1-30) in sequential order. TAs were instructed that the blending programme should be delivered alongside the book reading and sight word learning activities they had been delivering as part of a reading intervention programme (for a description of the intervention, see Burgoyne et al., 2012a).

\section{Assessments and procedure}

Children were assessed three times: at the start of the study (t1), after an 8-week control period (time 2; t2) and after 6 weeks of intervention (time 3; t3). The control period included school holidays as well as time in school with typical teaching. Assessments were conducted by the first author (KB) and two research assistants at the University of York, all of whom had training and experience in assessing children with DS. At each time point, testing was completed in a single session in a quiet room at the child's school. TAs were present during testing to support behaviour and communication where necessary.

\section{a Descriptive measures $(t)$}

- Letter-sound knowledge (YARC; Hulme et al., 2009): Children were asked to identify 32 individual letters and digraphs (alpha $=.98)$.

- Vocabulary: Children completed the Expressive and Receptive One-Word Picture Vocabulary Tests (EOWPVT; ROWPVT; Brownell, 2000). Children were required to name a series of pictures and to choose the correct pictures - from arrays of 4 - which matched a series of spoken words.

\section{b Outcome measures $(t I-t 3)$}

- Single-word reading was assessed using the YARC Early Word Recognition (EWR) test (Hulme et al., 2009; alpha = .98). A further set of words from the Test of Single-Word Reading were given to children scoring over 25.

- Phoneme blending with pictures: Children selected one of three pictures that matched a word spoken by the experimenter in 'robot' talk (i.e. saying the constituent phonemes sequentially, with a one-second gap between each). Two practice items were followed by 10 test items (alpha $=.67)$.

- Phoneme blending no pictures: Children were asked to name a word spoken by the experimenter in 'robot' talk. The test included two practice items and 12 test items (alpha $=.66$ ).

- Non-word Reading: Children were asked to read the names of 6 cartoon monsters: 'et', 'om', 'ip', 'neg', 'sab' and 'hic'. Two practice items were given before test items (alpha = .88). One point was awarded for each non-word read correctly.

- Sound isolation was assessed using the subtest from the YARC (Hulme et al., 2009), which asks children to identify initial ( 6 items) and final (6 items) phonemes in spoken non-words.

- Spelling: Ten words were presented as pictures to be named and spelled (alpha =.97). If no letters were correctly represented in the first two items the test was discontinued. Raw scores were calculated by awarding 1 point for each word spelt correctly. A Phonetic Spelling score was also derived, to assess how closely the orthographic representations of the consonants matched the target consonants: 4 points were awarded for each correct letter; 3 points for a letter that differed from the target consonant by only one phonetic feature (place, 
Table 3. Mean (and standard deviations) pre- and post-intervention raw scores on outcome measures $(n=10)$ with gain scores and $t$-values for changes in values across control $(t \mid-t 2)$ and intervention periods $(\mathrm{t} 2-\mathrm{t} 3)$.

\begin{tabular}{|c|c|c|c|c|c|c|c|c|c|}
\hline \multicolumn{3}{|l|}{$\mathrm{tl}$} & \multicolumn{2}{|l|}{$\mathrm{t} 2$} & \multicolumn{2}{|l|}{$\mathrm{t} l-\mathrm{t} 2$} & \multicolumn{2}{|l|}{ t3 } & $\mathrm{t} 2-\mathrm{t} 3$ \\
\hline $\begin{array}{l}\text { Test (maximum } \\
\text { score) }\end{array}$ & Mean (SD) & Range & Mean (SD) & Range & Gain & $\mathrm{t}(9)$ & Mean (SD) & Range & Gain $t(9)$ \\
\hline $\begin{array}{l}\text { Single word } \\
\text { reading (79) }\end{array}$ & $14.00(9.00)$ & $1-35$ & $14.00(9.36)$ & $4-35$ & 0.00 & 0.00 & $17.50(\mid 1.31)$ & $4-43$ & $3.504 .20 *$ \\
\hline $\begin{array}{l}\text { Sound isolation } \\
\text { (I2) }\end{array}$ & $2.70(3.83)$ & $0-10$ & $3.00(3.16)$ & $0-7$ & 0.30 & 0.28 & $4.50(3.92)$ & $0-11$ & $1.50 \quad 1.77$ \\
\hline $\begin{array}{l}\text { Phoneme } \\
\text { blending with } \\
\text { pictures (I0) }\end{array}$ & $7.70(1.83)$ & $5-10$ & $6.80(1.55)$ & $3-8$ & -0.90 & 1.06 & $9.20(1.48)$ & $6-10$ & $2.403 .42 *$ \\
\hline $\begin{array}{l}\text { Phoneme } \\
\text { blending no } \\
\text { pictures (I2) }\end{array}$ & $6.50(2.32)$ & $4-12$ & $5.70(1.95)$ & $3-9$ & -0.80 & 1.27 & $8.00(2.05)$ & $3-10$ & $2.303 .54^{*}$ \\
\hline $\begin{array}{l}\text { Non-word } \\
\text { reading (6) }\end{array}$ & $2.10(1.52)$ & $0-5$ & $2.50(1.27)$ & $1-5$ & 0.40 & 0.80 & $3.10(0.99)$ & $2-5$ & $0.60 \quad 1.62$ \\
\hline Spelling raw (10) & 0 & & ) & & 0.00 & 0.00 & & $0-4$ & $0.70 \quad 1.91$ \\
\hline $\begin{array}{l}\text { Spelling } \\
\text { phonetic (92) }\end{array}$ & $41.30(31.37)$ & $0-78$ & 48.30 (29.27) & $0-82$ & 7.00 & 1.29 & $55.10(26.57)$ & $0-83$ & $6.80 \quad 1.63$ \\
\hline
\end{tabular}

Note. $* p<.01$.

manner or voicing); 2 points for a partially represented digraph, or for a correct letter in the wrong position; and 1 point for a letter more than one phonetic feature away from the target consonant. Twenty-three consonants were scored, giving a total of 92 points.

c TA Questionnaire. At $\mathrm{t} 3$ TAs were asked to complete a questionnaire about their experiences delivering the intervention. A 7-point response scale was used to rate the extent to which TAs agreed $(1=$ disagree; 7 agree), with 8 statements related to intervention delivery and effectiveness (see Table 5 below).

\section{Results}

Table 3 shows the scores on measures of phonological and reading skills at $\mathrm{t} 1, \mathrm{t} 2$ and $\mathrm{t} 3$. As the length of the control ( $\mathrm{t} 1-\mathrm{t} 2)$ and intervention periods $(\mathrm{t} 2-\mathrm{t} 3)$ were not equal, gain scores were adjusted to take into account differences in time periods: dividing gain scores by the time lag in testing points ( 2.8 months in the control period versus 1.8 months in the intervention period) produced a comparable measure of gain per month.

Research Questions I and 2: Can a targeted teaching programme improve the phoneme blending skills of children with DS, and does the programme lead to gains in reading and spelling?

Figure 1 compares the gains made per month during the control and intervention periods $(95 \%$ confidence intervals included). As can be seen from the graph, children made very little progress over the control period; more progress was seen on all outcome measures during the intervention. Paired $t$-tests on the adjusted gain scores showed that gains per month made during the intervention 
Table 4. Case analysis of the gains made in word reading during the control $(\mathrm{t} l-\mathrm{t} 2)$ and intervention periods $(\mathrm{t} 2-\mathrm{t} 3)$.

\begin{tabular}{lrrrrl}
\hline Participant & $\mathrm{t}$ l & $\mathrm{t} 2$ & $\mathrm{t}$ - $-\mathrm{t} 2$ gain & $\mathrm{t} 3$ & $\mathrm{t} 2-\mathrm{t} 3$ gain \\
\hline 5 & 1 & 4 & 3 & 4 & 0 \\
9 & 9 & 7 & -2 & 8 & 1 \\
10 & 12 & 12 & 0 & 13 & 1 \\
7 & 10 & 12 & 2 & 14 & 2 \\
1 & 21 & 23 & 2 & 26 & 3 \\
2 & 9 & 4 & -5 & 8 & 4 \\
6 & 15 & 15 & 0 & 19 & 4 \\
8 & 14 & 12 & -2 & 17 & 5 \\
3 & 14 & 16 & 2 & 23 & 7 \\
4 & 35 & 35 & 0 & 43 & 8 \\
\hline
\end{tabular}

Table 5. Mean (standard deviations) for teaching assistant questionnaire ratings.

\begin{tabular}{ll}
\hline Question & Rating* \\
\hline a) The blending intervention was easy to deliver. & $6.80(0.42)$ \\
b) The child I work with has improved on the intervention activities. & $5.80(I .03)$ \\
c) The child I work with is more confident with the intervention activities. & $5.89(0.78)$ \\
d) I have seen the child I work with using a blending strategy more often & $5.60(0.97)$ \\
in reading contexts outside of the intervention. & $5.30(I .16)$ \\
e) The child I work with is now more able to sound out and blend new & \\
words when reading. & $7.00(0.00)$ \\
f) I have enjoyed delivering the intervention. & $6.80(0.42)$ \\
g) The child I work with has enjoyed taking part in the intervention. & $7.00(0.42)$ \\
h) I believe there is a benefit of doing this specific type of intervention.
\end{tabular}

Note. ${ }^{*} 1=$ disagree; $7=$ agree.

period were significantly larger than those made during the control period on blending (both with and without pictures) and on word reading. No significant effects were found on measures of sound isolation, non-word reading or spelling.

The gains in word reading for each child over the intervention period are presented in Table 4, ordered according to increasing gains. All but one of the children made progress in word reading during the course of the intervention, though there is considerable variability between children in the size of the gains made.

\section{Research Question 3: Do educators working with children with DS feel the programme is easy to implement, effective and worthwhile?}

Mean ratings (standard deviations) on the TA questionnaire are displayed in Table 5. Scores indicate that TAs felt that the intervention was easy to implement and enjoyable, and had benefits for the children's development.

\section{Discussion}

This study evaluated a 6-week prescribed programme of teaching designed to develop phoneme blending skills in a group of children with DS. The programme was delivered in the context of a 


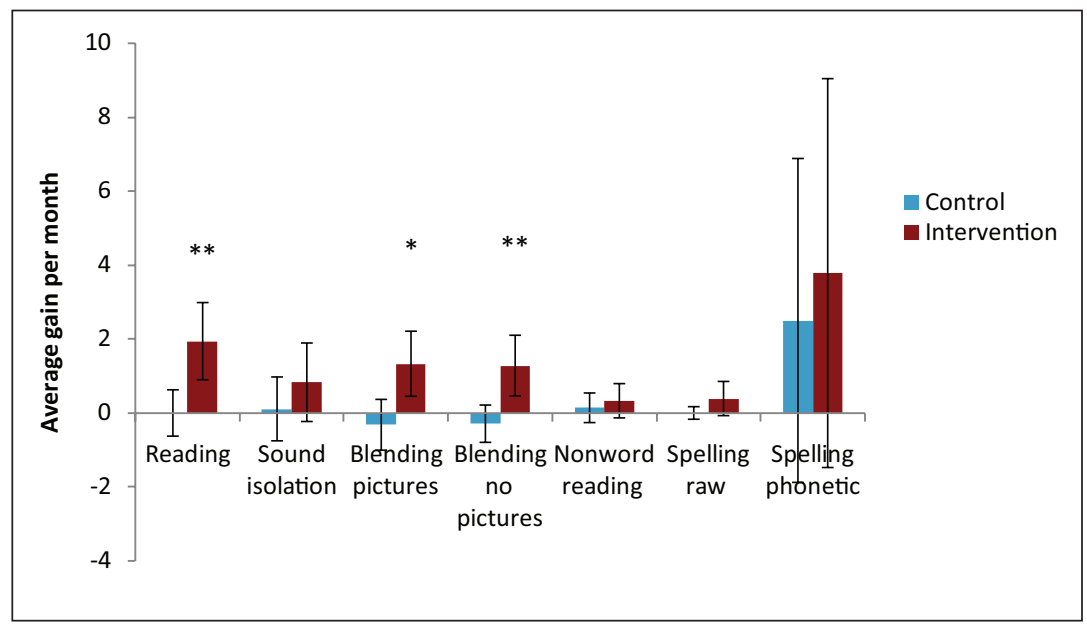

Figure I. Comparison of raw score gains made on each outcome measure over control and intervention periods accounting for time, with $95 \%$ confidence intervals. Note. $* p<.05 ; * * p<.01$.

wider programme of literacy, which included book reading and sight word instruction. Using a case series design in which children acted as their own controls, significant gains were seen on measures of phoneme blending skills (both with and without picture support). Gains also transferred to a measure of single word reading. There was no evidence of transfer to sound isolation, non-word reading or spelling skills.

The results of this study indicate that children with DS can learn to blend phonemes in words following targeted instruction over a relatively short period of time. Phoneme awareness is critical to the development of alphabetic reading skills; the ability to sound out and blend phonemes in words is an important strategy for readers to tackle new and unfamiliar words. Significant effects on word reading suggest that improving blending skills supported the development of a phonic reading strategy, which transferred to gains in reading. It is important to note, however, that no significant effects were found on a measure of non-word reading, argued to be a pure test of decoding ability, and that children were also engaged in book reading and sight word learning activities alongside the blending programme. Therefore it remains a possibility that children were reading real words using alternative strategies.

It is notable that significant gains in blending and word reading were observed following only six weeks of instruction. Consistent with previous research, gains made in word reading across the intervention phase were highly variable across the group (ranging between 0 and 8 words). This raises important questions about whether all children can benefit from this type of intervention, and who intervention should be aimed at. It is interesting to note that the child who did not progress on the word reading measure across the intervention period had both the lowest word reading and the lowest vocabulary scores at time 1 . Initial word reading has been identified as a significant predictor of growth in decoding (Lemons and Fuchs, 2010a), leading to the suggestion that this type of instruction may be most effective for those who have established some level of (sight word) reading ability. Language has also been identified as a significant predictor of response to phonicsbased intervention, both for typically-developing children (e.g. Whiteley et al., 2007) and for children with DS (e.g. Burgoyne et al., 2012a). It may be that children with limited existing reading skills and significant and pervasive language deficits are not yet at a stage where they are able to 
benefit from this type of intervention approach, and that alternative, more foundational, intervention may be more appropriate; it remains for future research to address this question.

Though children made gains in spelling during the intervention, no significant effects were seen on this measure. Potentially, this type of intervention may have benefits for spelling over longer periods of instruction. Scores on the spelling task were low at all assessment points. The nature of the spelling task placed demands on fine motor skills which affected children's performance on this test; future work should take this into account when developing measures of spelling ability by, for example, using magnetic letters or keyboards. Though the intervention activities did not explicitly target spelling, such activities could easily be incorporated into future work to increase the potential for improving spelling skills.

This work is also consistent with other research that demonstrates that TAs can be trained to deliver intervention effectively (Burgoyne et al., 2012a). Qualitative reports suggest that TAs delivering intervention find the teaching of phonics to be difficult, even after training (Burgoyne et al., 2012b; Carroll et al., 2011). The TAs in this study found the intervention to be easy and enjoyable to implement, perhaps because of its prescriptive nature. Responses to the TA questionnaire also lend further support (albeit subjective) to the efficacy of the teaching programme; TAs agreed with statements regarding improvements to children's abilities and confidence in the intervention activities, increased use of a blending strategy when reading outside of the intervention sessions and greater ability in sounding out and blending words. TAs also agreed that they could see the benefit of this type of intervention.

The teaching programme evaluated here could also be readily adapted for electronic delivery (e.g. via iPad or iPhone apps). There are an increasing number of apps available that aim to address specific reading skills in a programmed and structured way. Though rigorous evaluation of such programmes is needed, they have considerable potential as many children find them engaging and motivating and are able to attend to them for sustained periods of time.

There are a number of limitations to this study. The use of participants as their own historical controls has been applied in this study as in previous evaluations of reading intervention both for typically developing children (e.g. Duff et al., 2008) and for children with DS (e.g. Baylis and Snowling, 2012; Cologon et al., 2011). However, this design does not adequately control for threats to internal validity such as maturation and is therefore not sufficient to make strong claims regarding the efficacy of the intervention. Future work would benefit from the inclusion of a control group with which to compare progress. In addition, whilst the design of this study incorporated a number of strategies that support fidelity to intervention, objective assessment of this was limited to a single observation. Nonetheless this suggested that the intervention was implemented with a sufficient degree of fidelity. The small sample size also limits the extent to which the findings can be generalized to a wider sample and precludes a thorough investigation of factors that may contribute to differential response to the intervention.

\section{Conclusions}

Children with DS can learn to blend phonemes in words when provided with targeted instruction. Developments in phoneme blending skills can potentially transfer to gains in word reading. Thus, there is significant potential for prescriptive teaching to boost phoneme blending skills. These findings add to current evidence that supports the efficacy of phonics-based reading approaches, taught within comprehensive programmes of literacy instruction, with children with DS (e.g. Burgoyne et al., 2012a; Goetz et al., 2008; Lemons and Fuchs, 2010b). This type of intervention can be delivered easily and effectively by TAs already working in the children's classrooms. 


\section{Acknowledgements}

Research assistance was provided by Dea Nielson and Sophie Brigstocke. Lauren James made a significant contribution to the development of the intervention materials. Our thanks go to the schools, TAs, children and families who took part in the research.

\section{Funding}

This project was supported by the Big Lottery Fund, a Nuffield summer student bursary and Down Syndrome Education International.

\section{References}

Baylis P and Snowling M (2012) Evaluation of a phonological reading programme for children with Down Syndrome. Child Language Teaching and Therapy 28: 39-56.

Brownell R (2000) Expressive and receptive one word picture vocabulary tests. 2nd edition. Novato, CA: Academic Therapy Publications.

Burgoyne K, Duff FJ, Clarke P, Buckley S, Snowling MJ, and Hulme C (2012a) Efficacy of a reading and language intervention for children with Down syndrome: A randomized controlled trial. Journal of Child Psychology and Psychiatry 53: 1044-53.

Burgoyne K, Duff FJ, Clarke P, Smith G, Buckley S, Snowling MJ, and Hulme C (2012b) A reading and language intervention for children with Down Syndrome: Teaching handbook. Cumbria, UK: Down Syndrome Education International.

Carroll JM, Bowyer-Crane C, Duff FJ, Snowling MJ, and Hulme C (2011) Developing language and literacy: Effective intervention in the early years. Malden, MA: John Wiley.

Cologon K, Cupples L, and Wyver S (2011) Effects of targeted reading instruction on phonological awareness and phonic decoding in children with Down syndrome. American Journal of Intellectual and Developmental Disabilities 116: 111-29.

Department for Education and Skills (DfES) (2007) Letters and sounds: Principles and practice of high quality phonics. London: Department for Education and Skills.

Duff FJ, Fieldsend E, Bowyer-Crane C, Hulme C, Smith G, Gibbs S, and Snowling MJ (2008) Reading with vocabulary intervention: Evaluation of an instruction for children with poor response to reading intervention. Journal of Research in Reading 31: 319-36.

Fidler D, Most DE, and Guiberson MM (2005) Neuropsychological correlates of word identification in Down syndrome. Research in Developmental Disabilities 26: 487-501.

Goetz K, Hulme C, Brigstocke S, Carroll JM, Nasir L, and Snowling M (2008) Training reading and phoneme awareness skills in children with Down syndrome. Reading and Writing 21: 395-412.

Hulme C, Stothard SE, Clarke P, Bowyer-Crane C, Harrington A, Truelove E, and Snowling MJ (2009) York assessment of reading for comprehension: Early reading. London: GL Assessment.

Hulme C, Goetz K, Brigstocke S, Nash H, Lervag A, and Snowling M (2012) The growth of reading skills in children with Down syndrome. Developmental Science 15: 320-29.

Kaderavek JN and Justice LM (2010) Fidelity: An essential component of evidence-based practice in speechlanguage pathology. American Journal of Speech-Language Pathology 19: 369-79.

Kay-Raining Bird E and Chapman RS (2011) Literacy development in childhood, adolescence, and young adulthood in persons with Down syndrome. In: Burack J, Hodapp R, Iarocci G, and Zigler E (eds) The Oxford handbook of intellectual disability and development. 2nd edition. Toronto: Oxford University Press, 184-99.

Kay-Raining Bird E, Cleave PL, and McConnell L (2000) Reading and phonological awareness in children with Down syndrome: A longitudinal study. American Journal of Speech Language Pathology 9: 319-30.

Laws G and Gunn D (2002) Relationships between reading, phonological skills and language development in individuals with Down syndrome: A five year follow-up study. Reading and Writing: An Interdisciplinary Journal 15: 527-48. 
Lemons CJ and Fuchs D (2010a) Phonological awareness of children with Down syndrome: Its role in learning to read and the effectiveness of related interventions. Research in Developmental Disabilities 31: 316-30.

Lemons CJ and Fuchs D (2010b) Modelling response to reading intervention in children with Down syndrome: An examination of predictors of differential growth. Reading Research Quarterly 45: 134-68.

Muter V, Hulme C, Snowling MJ, and Stevenson J (2004) Phonemes, rimes, vocabulary, and grammatical skills as foundations of early reading development: Evidence from a longitudinal study. Developmental Psychology 40: 663-81.

National Reading Panel (NRP) (2000) Report of the National Reading Panel: Reports of the subgroups. Washington, DC: National Institute of Child Health and Human Development Clearing House.

Roch M and Jarrold C (2008) A comparison between word and nonword reading in Down syndrome: The role of phonological awareness. Journal of Communication Disorders 41: 305-18.

Rose J (2006) Independent review of the teaching of early reading: Final report. London: Department for Education and Skills.

Torgerson CJ, Brooks G, and Hall G (2006) A systematic review of the research literature on the use of systematic phonics in the teaching of reading and spelling. London: Department for Education and Skills.

van Bysterveldt A, Gillon G, and Moran C (2006) Enhancing phonological awareness and letter knowledge in preschool children with Down syndrome. International Journal of Disability, Development and Education 53: 301-29.

Whiteley HE, Smith D, and Connors L (2007) Young children at risk of literacy difficulties: Factors predicting recovery from risk following phonologically-based intervention. Journal of Research in Reading 30: 249-69. 


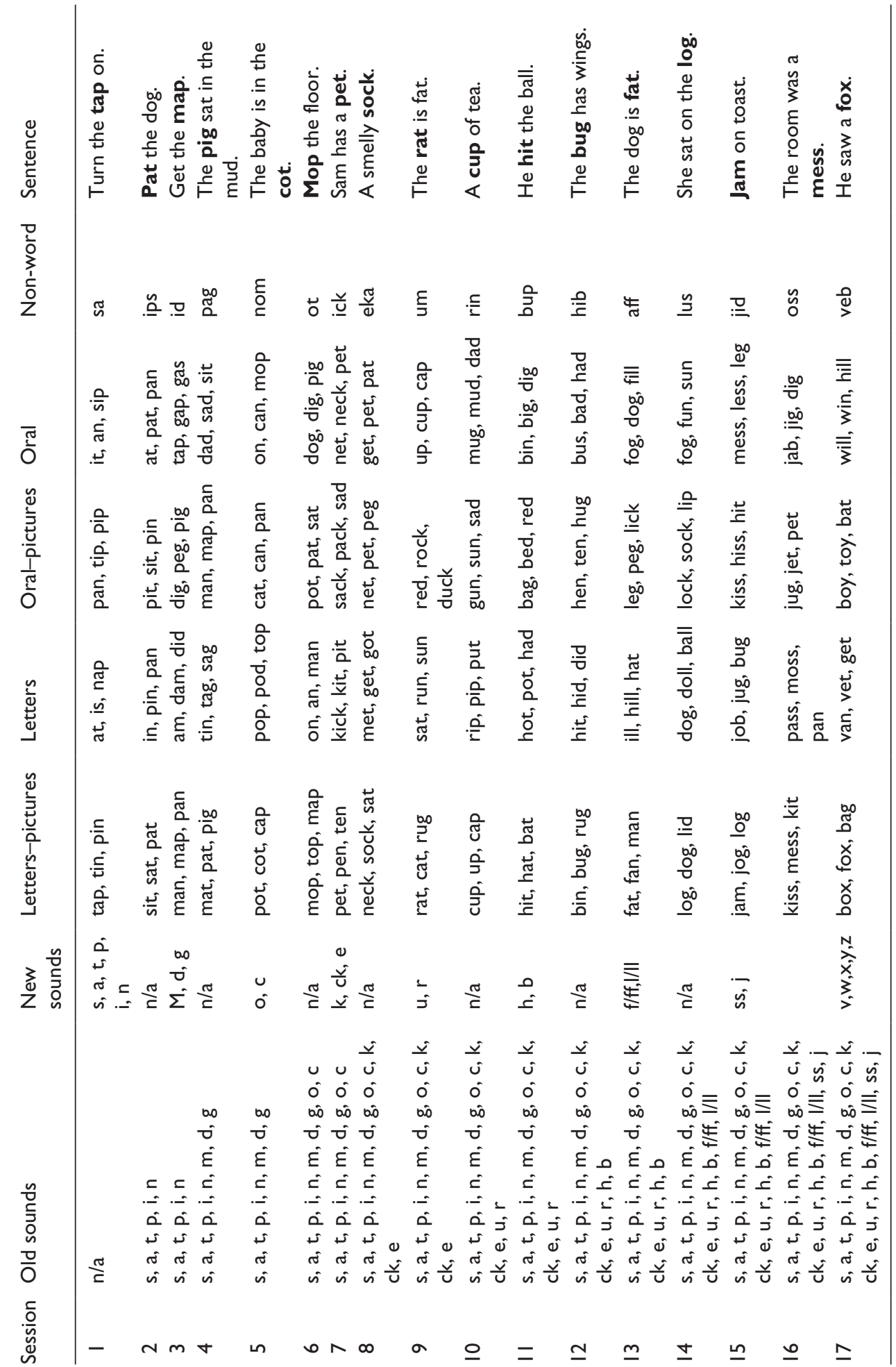




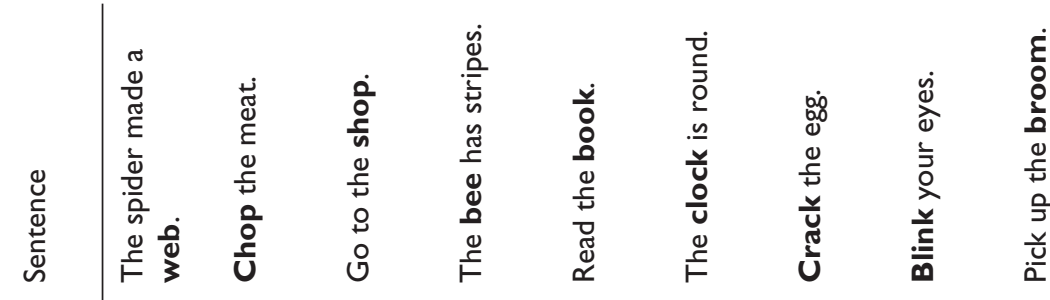

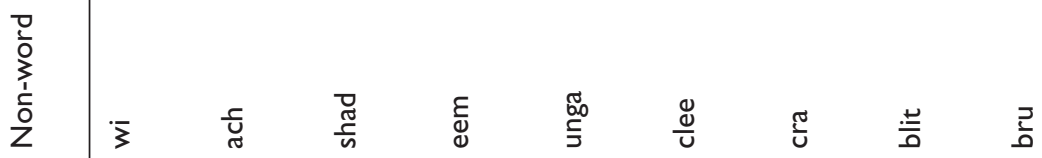

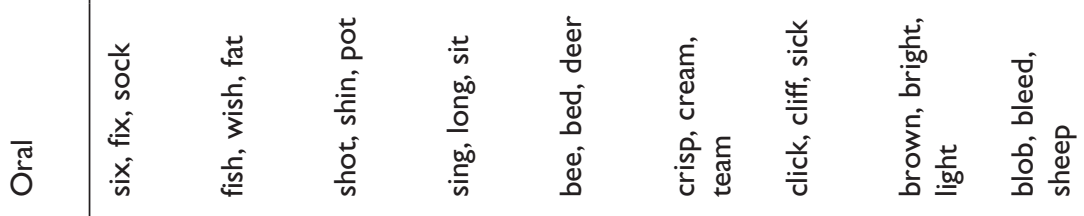

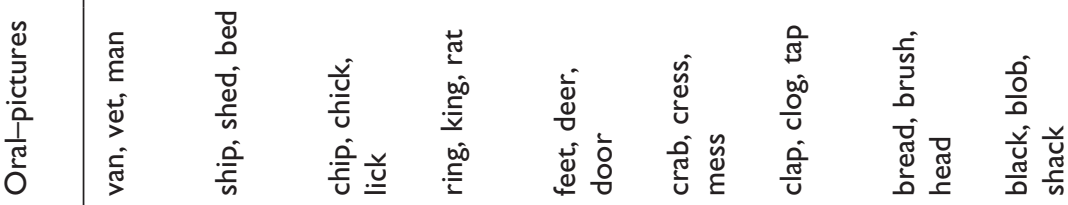

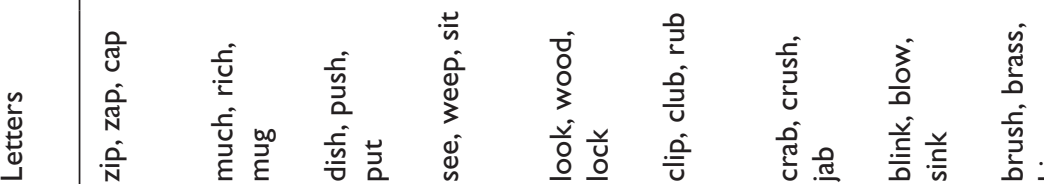

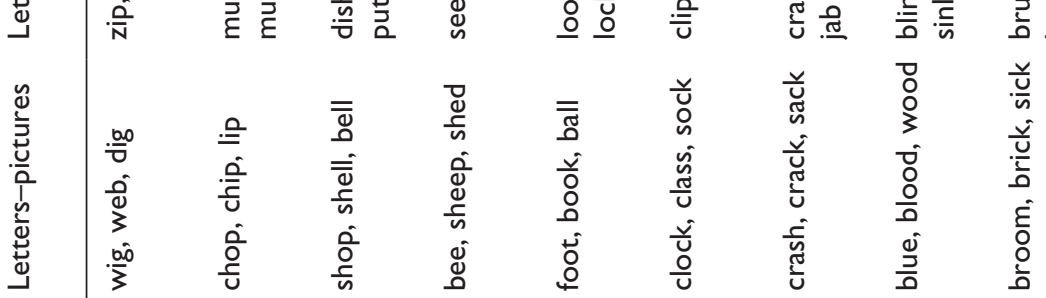

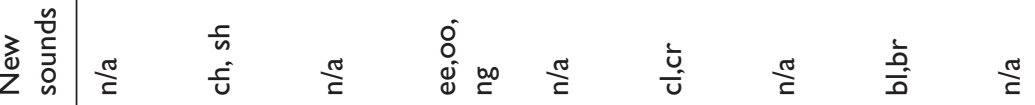

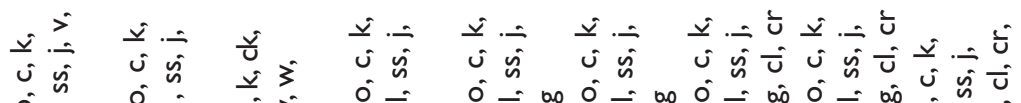

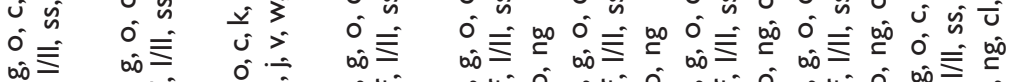

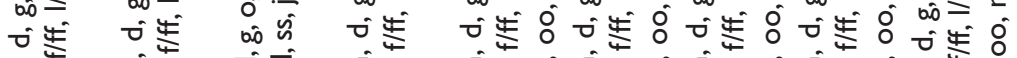

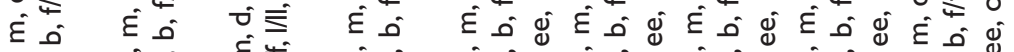

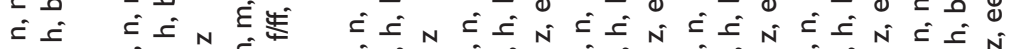

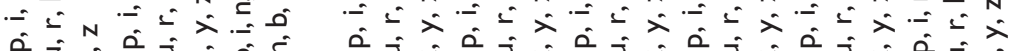

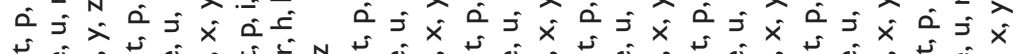

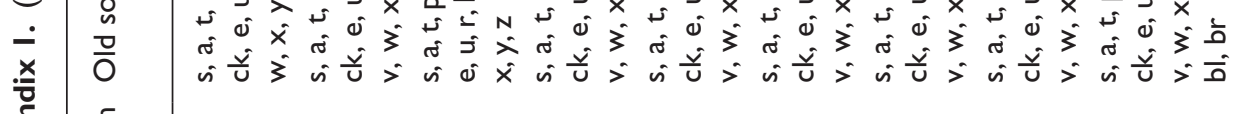




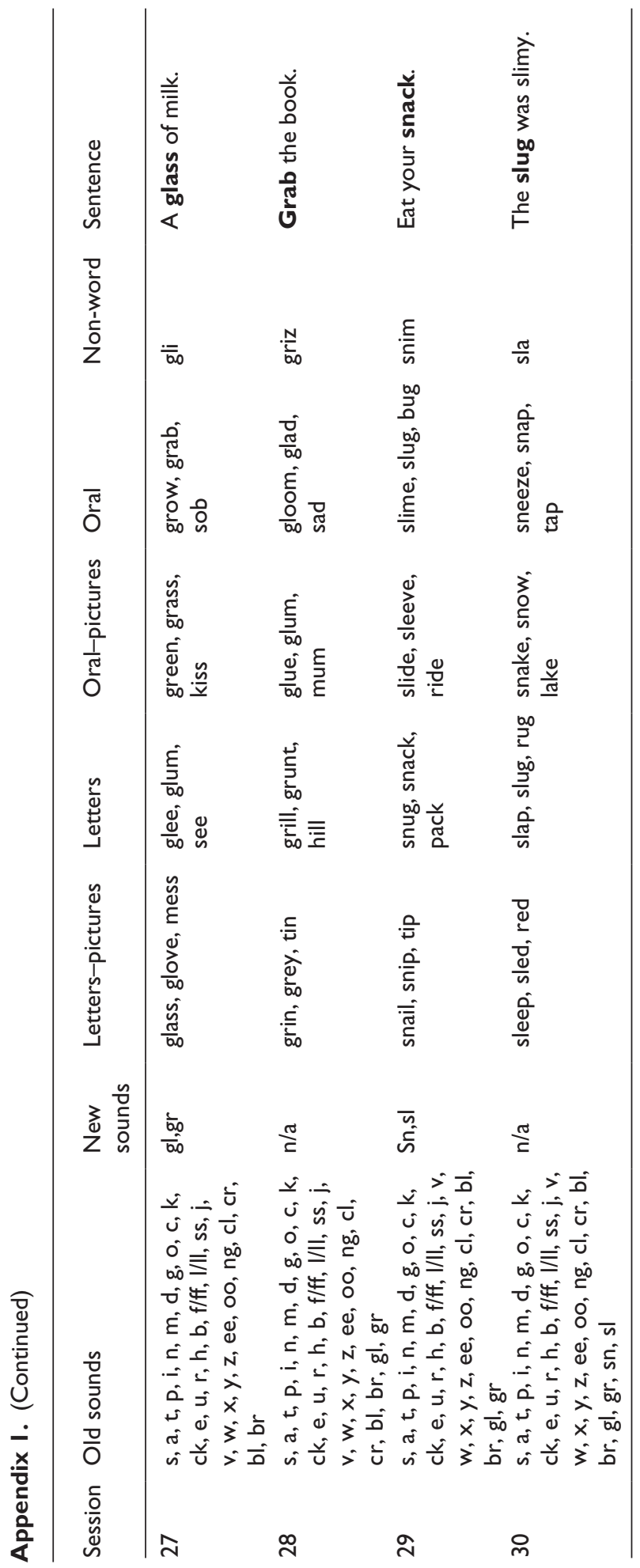




\section{Appendix 2.}

\section{Script and resources for teaching session I}

\section{Session 1}

Introduce the session: 'We are going to play some games with letters and sounds. Are you ready? First we are going to play some games with letters so let's get our letter card out.' Get out the letter grid. 'Here it is. Are you ready?'

\section{Game I: Visual blending with pictures: Words tap, tin, pin}

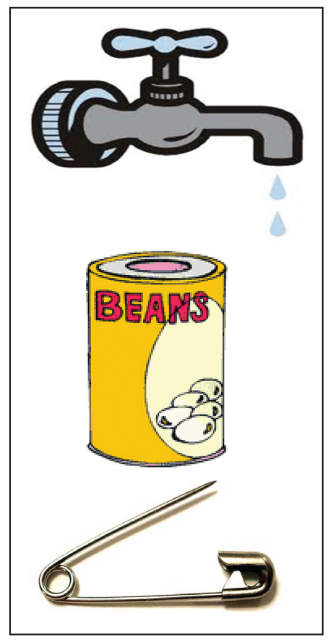

1. Show the child the picture card. Say, 'Here are three pictures; let's say what these pictures are.' Point to each picture and say the words; encourage the child to say them after you. 'Tap, Tin and Pin.'

2. Say 'I'm going to spell out one of these words with my letters. I want you to say the sound for each letter as I put it down on the table. When I have put all the letters down, I want you to sound out the letters and blend them together to make the word. See if you can guess which word I am spelling. When you guess, say the word and point to the right picture.'

3. Put out the first letter for the word 'tin'. Encourage the child to say the sound ' $t$ '. Say, 'Well done, that is a " $t$ " '. Repeat for the next two letters. Provide as much support as needed.

4. Ask the child to sound out each letter, and then to blend the sounds together: 'Say the sounds for all the letters, then put them together to make the word.' Provide the child with as much support as needed, for example, repeat the sounds, encourage the child to say the sounds faster, get the child to say the sounds after you.

5. When the child says the word and has chosen the matching picture, repeat the activity for the remaining two pictures.

6. If the child makes an incorrect guess, sound out the word again and support them in choosing the correct picture. Explain why this is correct, for example, . 'Our letters are t-i-n.' When we put the letters together, we make the word 'tin' - can you say that? Which picture is 'tin'? Well done, you are right! Let's do the next one.' Repeat the activity with the remaining two words. 


\section{Game 2: Visual blending (no pictures): Words at, is, nap}

1. Say, 'Now we are going to play another game with our letters - this one doesn't have any pictures so we need to concentrate. I'm going to spell out a word with my letters. I want you to say the sound for each letter, and then put the sounds together to guess the word I am spelling. Are you ready?'

2. Spell out the first word, a-t. Encourage the child to sound out each letter. Ask the child to blend the sounds together and say the word; 'What is the word?'

3. Provide the child with as much support as needed, for example, repeat the sounds, encourage the child to say the sounds faster, get the child to say the sounds after you.

4. When the child correctly guesses the word, repeat the activity for the remaining two words.

5. If the child makes an incorrect guess, model the correct answer, for example, point to each letter and say, 'A-t; if we put those sounds together, we get the word 'at'. A-t, at. Can you say that? Well done. Let's try the next one.' Repeat the activity with the remaining two words.

6. Say, 'You are doing some brilliant work today, well done. We are going to play some listening games now. It's really important that we listen carefully - are you ready?'

\section{Game 3: Oral blending with pictures: Words pan, tip, pip}

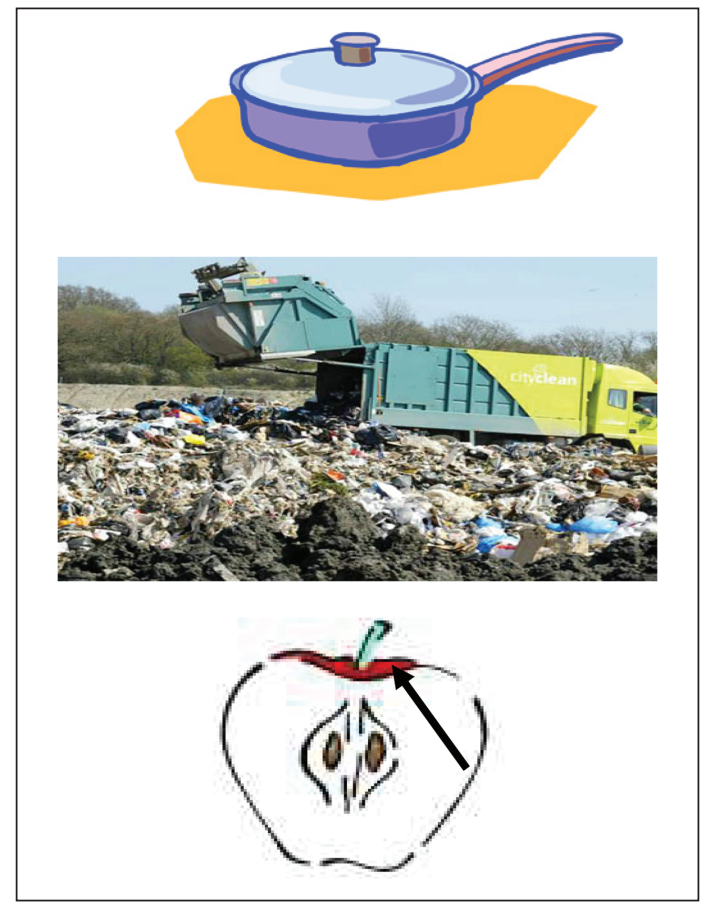

1. Show the child the picture card. Say, 'Here are three pictures; let's say what these pictures are.' Point to each picture and say the words; encourage the child to say them after you. 'Pan, Tip and Pip'.

2. Say, 'I'm going to say the name of one of these pictures using a silly voice. See if you can guess which word I am saying. When you guess, say the word and point to the right picture.' 
3. Say one of the words by sounding the word out, for example, p-i-p. Encourage the child to look at your face you as you sound out the word. Ask the child to blend the sounds together and choose the matching picture; say, 'Which word did I say?'

4. Provide the child with as much support as needed, for example, repeat the sounds, say them more slowly, get the child to say the sounds after you.

5. When the child makes the correct guess, repeat the activity for the remaining two pictures.

6. If the child makes an incorrect guess, sound out the word again and support them in choosing the correct picture. Explain why this is correct, for example, 'Listen again; p-i-p. When we put the sounds together, these sounds make the word 'pip' - can you say that? Which picture is 'pip'? Well done, you are right! Let's do the next one.' Repeat the activity with the remaining two words.

\section{Game 4: Oral blending (no pictures): Words it, an, sip}

1. Say, 'Now we are going to play another listening game - this one doesn't have any pictures so we have to listen even more carefully. I'm going to say a word in my silly voice and I want you to tell me what word I am saying. Are you ready?'

2. Say the first word by sounding it out, for example, i-t. Encourage the child to look at your face as you sound out the word. Ask the child to blend the sounds together and say the word; say, 'What word did I say?'

3. Provide the child with as much support as needed, for example, repeat the sounds, say them more slowly, get the child to say the sounds after you.

4. When the child correctly guesses the word, repeat the activity for the remaining two words.

5. If the child makes an incorrect guess, model the correct answer, for example, 'I-t; if we put those sounds together, we get the word 'it'. I-t, it. Can you say that? Well done. Let's try the next one.' Repeat the activity with the remaining two words.

\section{Game 5: Non-word reading}

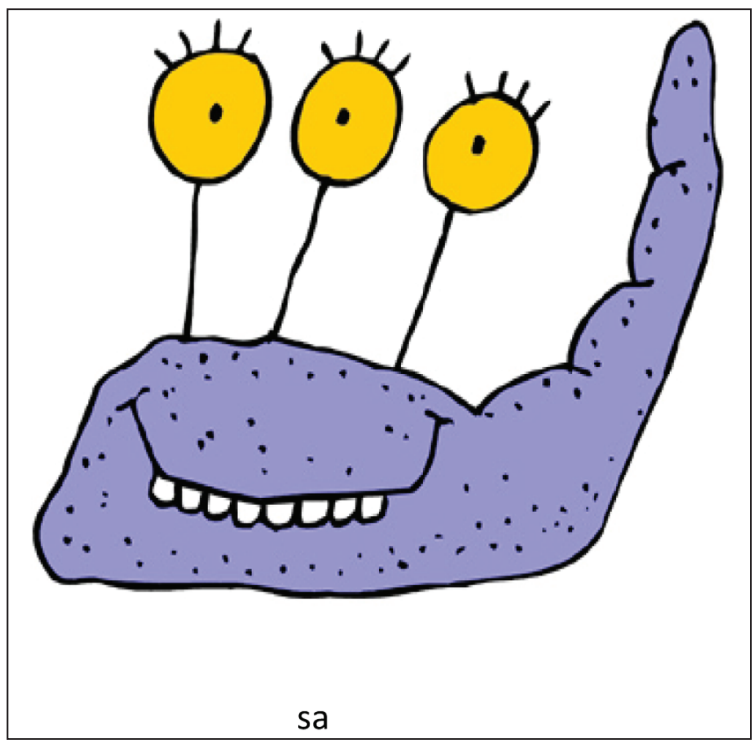


1. Say, 'Now we are going to play a game with monsters, are you ready to see a scary monster?' Show the child the monster picture and non-word. Say, 'Look, the monster's name is written underneath the picture, let's try and read it. Remember this is a monster so he will have a silly made-up name, not a real name.'

2. Encourage the child to sound out each letter, and then to blend the letter-sounds together to make the monster's name, for example, 'Let's sound this out. What sound does this first letter make? You're right, it is s. And the second letter is? Yes, it is a. So we have s and a. What word does that make - what is the monster's name?'

3. Provide as much support as the child needs to name the monster, for example, repeat the sounds, encourage the child to say the sounds faster, get the child to say the sounds after you.

4. If the child makes an incorrect guess, model the correct answer, for example, point to each letter and say, 'S-a; if we put those sounds together, we get the name 'sa'. S-a, sa; the monster is called Sa. Can you say that? Well done.'

\section{Game 6: Sentence reading}

\section{Turn the tạp on.}

1. Say, 'You have done a brilliant job and worked very hard. We have one more game to play. We are going to read a sentence together. One of the words in the sentence is a word we are going to sound out. Shall we have a look?'

2. Show the child the sentence strip. Say, 'This is our sentence today; let's read it'. Encourage the child to read the sentence.

3. When the child gets to the 'special' word (decodable word in bold with sound buttons) say, 'This is our special word we are going to sound out'. Point to the first letter and say 'what sound does this letter make?' Repeat with the remaining letters. Encourage the child to blend the sounds together: 'What is the word? Blend the sounds together to make the word.'

4. Provide as much support as the child needs to read the word, for example, repeat the sounds, encourage the child to say the sounds faster, get the child to say the sounds after you.

5. If the child makes an incorrect guess, model the correct answer, for example, point to each letter and say, 'T-a-p; if we put those sounds together, we get the word 'tap'. T-a-p, tap; the word is tap. Can you say that? Well done.'

6. Re-read the sentence with the child.

7. When you have finished, praise the child and tell them you will play some more games tomorrow. 